\title{
Peyzaj Çalışmalarında Kullanılan Bazı Bitkilerde Klorofil Miktarının Değişimi
}

\author{
Mehmet ÇETIN \\ Kastamonu Üniversitesi, Mühendislik ve Mimarlık Fakültesi, Peyzaj Mimarlığı Bölümü, Kastamonu \\ Sorumlu yazar: mcetin@kastamonu.edu.tr
}

Geliş Tarihi: 12.02.2016

\begin{abstract}
Özet
Fotosentez, klorofil taşıyan canlılarda ışık enerjisi kullanılarak organik bileşiklerin üretilmesi olayı olup canlılar için hayati önem taşıyan fotosentezde başlıca etken klorofildir. Yapraklardaki klorofil miktarı pek çok çevresel faktörden etkilenerek değişiklik göstermektedir. Bu çalışmada peyzaj amaçlı olarak yetiştirilen; Yukka (Yucca filamentosa), Dağ muşmulası (Cotoneaster franchetti), Mahonya (Mahonia aquifolium), Gül (Rosa sp.), Taflan (Euonymus japonica), Orman Sarmaşı̆̆ı (Hedera helix), Süsen (Iris sp.), Kurtbağrı (Ligustrum vulgare), Süs Lahanası (Brassica oleracea), Karayemiş (Laurocerasus officinalis), Menekşe (Viole sp.), Sarı Çiçekli Yasemen (Jasminum fruticans) olmak üzere toplam 12 tür üzerinde, güneş gören ve gölgede kalan yapraklar üzerinde yapılan ölçümlerle yapraklardaki klorofil miktarı belirlenmiş ve klorofil miktarının türe ve güneşlenmeye bağlı değişimi incelenmiştir. Çalışma sonucunda türler arasında istatistiki olarak \%99,9 güven düzeyinde anlamlı farklar tespit edilirken, güneşlenmeye bağlı olarak yapraktaki klorofil miktarı bakımından sadece orman sarmaşı̆̆ı, kurtbağrı ve sarı çiçekli yasemen bakımından güneşlenmeye bağlı olarak yapraklar arasında istatistiksel olarak en az \%95 güven düzeyinde anlamlı farklılıklar olmadığı, diğer türlerde ise güneş alan yapraklar ile gölge koşullarında yetişen yapraklar arasında klorofil miktarı bakımından istatistiksel olarak en az $\% 95$ güven düzeyinde anlamlı farklılıklar olduğu tespit edilmiştir.
\end{abstract}

Anahtar Kelimeler: Peyzaj, Bitki, Klorofil, Güneşlenme

\section{Changes in the Amount of Chlorophyll in Some Plants of Landscape Studies}

\section{Abstract}

Photosynthesis, chlorophyll bearing the production of organic compounds using light energy is alive in the event of chlorophyll in photosynthesis is the key factor of vital importance for living creatures. The amount of chlorophyll in the leaves vary influenced by many environmental factors. Grown for landscaping in this study; Yucca (Yucca filamentosa), Cotoneaster (Cotoneaster franchetti), Mahonia (Mahonia aquifolium), Rose (Rosa sp.), Euonymus (Euonymus japonica), English ivy (Hedera helix), Iris (Iris sp.), Common privet (Ligustrum vulgare), Ornamental cabbage (Brassica oleracea), Cherry laurel (Laurocerasus officinalis), Violet (Viole sp), Common jasmine (Jasminum fruticans) over 12 species in total, including, sunlit and shaded leaves remaining on the amount of chlorophyll in the leaves with measurements made determined and species-dependent variation of the amount of chlorophyll and insolation were investigated. The results of this study, the species statistically significant differences were detected in $99.9 \%$ confidence level. Depending on the amount of chlorophyll in leaves only by the insolation; English ivy, Common privet and Common jasmine statistical terms between the sheets, was depending on where the sun is observed no significant differences in the levels of at least $95 \%$ confidence. In other species it was found to be statistically at least $95 \%$ confidence level, significant differences in the amount of chlorophyll in leaves grown in sunlight leaves with shadow conditions.

Keywords: Landscape, Plant, Chlorophyll, Insolation

\section{Giriş}

Günümüzde nüfus artışına paralel olarak, plansız ve sağlıksız gelişen kentlerimizde doğaya ve yeşile olan özlem giderek artmaktadır (Küçük ve Gül, 2005). Kent insanının doğaya olan özlemi, rekreasyonel taleplerini karşılayacak yeterli alanların bulunmayışı, doğanın bir parçası olan insanı, yaşadığ 1 mekanı ve çevresini düzenlemeye itmekte, buna paralel olarak açık ve yeşil alanların önemi de giderek artmaktadır (Sevik ve ark., 2012). Günümüz modern yaşamında bitki varlığı şehirlerin kalitesinin ve yaşanılırlığının bir göstergesi kabul edilmeye başlamıştır (Ozturk ve Bozdogan, 2015). 
Bitkiler bulundukları ortamda pek çok fonksiyonu yerine getirirler. Hava kirliliğini azaltır (Papinchak ve ark., 2009; Tani ve Hewitt, 2009; Yang ve ark., 2009; Ozturk ve Bozdogan, 2015; Sevik ve ark., 2015), gürültüyü azaltır (Yigit ve ark., 2014), estetik değeri artırır (Sevik ve ark., 2014), psikolojik olarak olumlu yönde etkiler (Belkayali ve Kesimoglu, 2015; Cetin, 2015a; Cetin, 2015b), enerji tasarrufu sağlar (Cetin, 2015c), önemli bir ekonomik kaynaktır (Sevik, 2011; Sevik, 2012), erozyonu önler (Turna ve Guney, 2009), rüzgarın hızını azaltır, toprağı kökleri ile tutarak yağışların ve akarsuların toprağ taşımasını önler, yaban hayatı ve av kaynaklarını korur. Bitkilerin bulunduğu açık yeşil alanlar hem yetişkinler hem de çocuklar için önemli aktivite alanlarıdır (Tekce ve ark., 2010; Talay ve ark., 2010). Bununla beraber iç mekanlarda bulunan bitkiler, bu alanlarda çalışan insanların verimliliği artırır (Djukanovic, 2002), kişileri psikolojik olarak rahatlatır, stres ve olumsuzluk duygularını azaltır (Lohr ve ark., 1996; Chang ve Chen, 2005; Burchett ve ark., 2014).

Ancak bu fonksiyonların yanında bitkilerin en önemli görevi besin zincirinin temelini oluştururlar. Neredeyse bütün canlı yaşamı fotosentez yapan yeşil bitkilere bağlidır. Fotosentez, klorofil taşıyan canlılarda 1 şı enerjisi kullanılarak organik bileşiklerin üretilmesi olayıdır. Fotosentez için klorofil ile birlikte güneşe ihtiyaç duyulmaktadır. Klorofil 1 şık enerjisini absorbe eder ve kimyasal enerjiye çevirir (Yakar ve Bilge, 1987). Böylece klorofil diğer tüm canlıların yaşaması için gerekli olan oksijen ve besin maddelerinin üretildiği fotosentez olayının gerçekleșmesini sağlar. Bunun yanında klorofil bitkilere yeşil rengi veren pigmenttir. Ancak, klorofil miktarının değişimine sebep olan faktörlerin belirlenmesi, bitki sağlığından stres faktörlerine kadar pek çok çalışmaya altlık oluşturması açısından önem taşımaktadır.

$\mathrm{Bu}$ çalışmada bazı bitkilerdeki renk değişiminin klorofil miktarı ile olan ilişkisinin belirlenmesi amaçlanmıştır. $\mathrm{Bu}$ amaçla seçilen 13 adet tür üzerinde, günün büyük kısmını güneş alan kısımda geçiren yapraklarda ve günün büyük kısmında gölgede kalan yapraklarda ölçümler yapılarak klorofil miktarının tür ve güneşlenmeye bağlı değişimi belirlenmiştir.

\section{Materyal ve Yöntem}

Çalışmanın amacı, yapraklarda klorofil miktarının değişiminin bitki türü ve güneşlenmeye bağl1 olarak belirlenmesidir. $\mathrm{Bu}$ amaçla çalışma, peyzaj çalışmalarında siklıkla kullanılan; Yukka (Yucca filamentosa), Dağ muşmulası (Cotoneaster franchetti), Mahonya (Mahonia aquifolium), Gül (Rosa sp.), Taflan (Euonymus japonica), Orman Sarmaşığı (Hedera helix), Süsen (Iris sp.), Kurtbağrı (Ligustrum vulgare), Süs Lahanas1 (Brassica oleracea), Karayemiş (Laurocerasus officinalis), Menekșe (Viole sp.) ve Sarı Çiçekli Yasemen (Jasminum fruticans) olmak üzere toplam 12 tür üzerinde gerçekleştirilmiştir.

Ölçümler her bir türden en az 5 birey üzerinde gerçekleştirilmiştir. Her bir birey üzerinde, belirgin şekilde gün boyu güneş alabilecek konumda olan yapraklardan 10 adet ve bitkinin iç kısımlarında bulunan ve bundan dolayı yoğun gölge koşullarında yetişen 10 adet olmak üzere toplam 20 adet yaprakta, yaprağın orta kısmında, damarlar üzerine gelmeyecek noktadan klorofil ölçümleri yapılmıştır. Ölçümler Şubat ayı içerisinde öğlen saatlerinde gerçekleştirilmiştir.

Ölçümler Apogee CCM-200 marka klorofilmetre ile gerçekleştirilmiş ve Chlorophyll Concentration Index (cci) biriminde sonuçlar elde edilmiştir.

\section{Bulgular}

Yapılan ölçümlere göre tür bazında en yüksek, en düşük ve ortalama değerler ile standart sapma değerleri Tablo 1.'de, Tablo1'deki ortalama verilere bağlı olarak hazırlanan grafik Şekil 1'de verilmiştir. 
Tablo 1. Klorofil miktarının türe ve güneşlenmeye bağlı değişimi

\begin{tabular}{|c|c|c|c|c|c|c|c|c|c|}
\hline \multirow{2}{*}{ Tür } & \multicolumn{4}{|c|}{ Güneș } & \multicolumn{4}{|c|}{ Gölge } & \multirow{2}{*}{ F Values } \\
\hline & Min & Mak & Ortalama & St.Sp. & Min & Mak & Ortalama & St.Sp. & \\
\hline Yukka & 101.7 & 133.2 & $117.3 \mathrm{f}$ & 11.6 & 136.0 & 145.4 & $140.3 \mathrm{~g}$ & 3.4 & $35.940 * * *$ \\
\hline $\begin{array}{l}\text { Dağ } \\
\text { muşmulası }\end{array}$ & 25.6 & 57.4 & $33.4 \mathrm{~b}$ & 12.8 & 35.9 & 61.7 & $51.5 \mathrm{~cd}$ & 11.7 & $10.921 * *$ \\
\hline Mahonya & 53.2 & 59.9 & $56.2 \mathrm{~d}$ & 2.4 & 34.7 & 45.2 & $38.4 \mathrm{~b}$ & 4.0 & $148.951 * * *$ \\
\hline Gül & 16.1 & 22.7 & $20.1 \mathrm{a}$ & 2.3 & 35.8 & 49.0 & $44.2 \mathrm{bc}$ & 5.0 & $191.635 * * *$ \\
\hline Taflan & 106.0 & 167.6 & $140.9 \mathrm{~g}$ & 24.4 & 38.3 & 55.1 & $47.4 \mathrm{bc}$ & 7.0 & $136.030 * * *$ \\
\hline $\begin{array}{l}\text { Orman } \\
\text { Sarmaşığ } 1\end{array}$ & 51.9 & 92.2 & $73.4 \mathrm{e}$ & 15.7 & 72.2 & 115.0 & $88.5 \mathrm{f}$ & 17.3 & $4.209 \mathrm{~ns}$ \\
\hline Süsen & 42.3 & 58.7 & $49.3 \mathrm{~cd}$ & 6.1 & 52.3 & 68.8 & $57.8 \mathrm{~d}$ & 6.0 & $9.780 * *$ \\
\hline Kurtbağrı & 49.6 & 94.6 & $70.9 \mathrm{e}$ & 17.9 & 38.8 & 85.7 & $60.0 \mathrm{~d}$ & 18.4 & $1.811 \mathrm{~ns}$ \\
\hline $\begin{array}{l}\text { Süs } \\
\text { Lahanas1 }\end{array}$ & 11.5 & 18.7 & $14.9 \mathrm{a}$ & 2.6 & 20.5 & 29.3 & $24.8 \mathrm{a}$ & 3.1 & $59.646 * * *$ \\
\hline Karayemiş & 91.0 & 131.5 & $112.9 \mathrm{f}$ & 13.6 & 65.8 & 99.6 & $78.8 \mathrm{e}$ & 13.0 & $32.764 * * *$ \\
\hline Menekşe & 15.8 & 22.9 & $18.8 \mathrm{a}$ & 2.8 & 18.4 & 29.9 & $22.9 \mathrm{a}$ & 4.7 & $5,663 *$ \\
\hline $\begin{array}{l}\text { Sar1 } \\
\text { Çiçekli } \\
\text { Yasemen }\end{array}$ & 37.6 & 43.7 & $39.7 b c$ & 2.4 & 35.2 & 41,8 & $38,5 b$ & 2.5 & $1.156 \mathrm{~ns}$ \\
\hline$F$ Values & & & $123.834 * * *$ & F Valu & & & $112.941 * * *$ & & \\
\hline
\end{tabular}

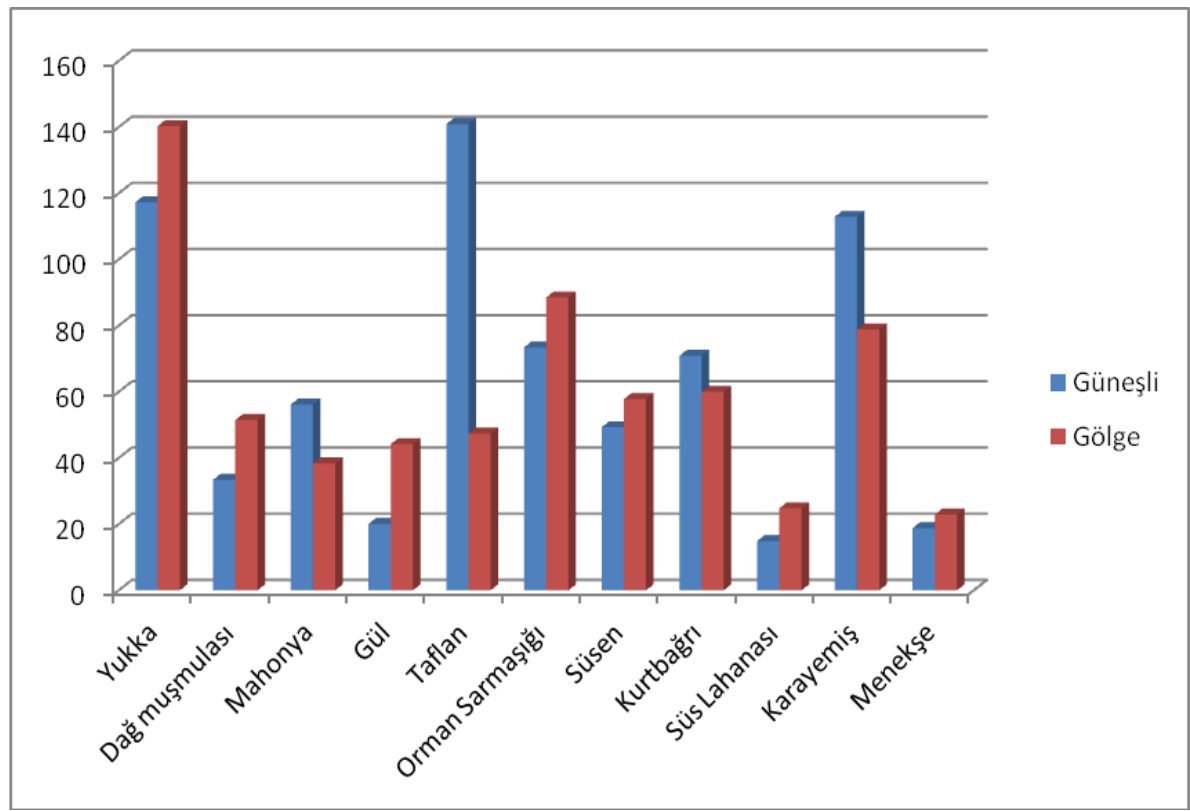

Şekil 1. Klorofil miktarının türe ve güneşlenmeye bağlı değişimi

Yapılan Varyans analizi sonucunda türler arasında hem güneş yapraklarındaki hem de gölge yapraklarındaki klorofil miktarı bakımından \%99.9 güven düzeyinde anlamlı farklılıklar olduğu belirlenmiş ve bunun üzerine yapılan Duncan testi sonucu oluşan gruplaşmalar Tablo'da verilmiştir. Güneş alan yapraklarda en yüksek ortalama klorofil değeri $140.9 \mathrm{ccl}$ ile taflanda, en düşük klorofil değeri ise $14.9 \mathrm{ccl}$ ile süs lahanasında belirlenmiştir. Gölge koşullarındaki yapraklarda ise en yüksek klorofil değeri $140.3 \mathrm{ccl}$ ile yine taflanda, en düşük klorofil değeri ise 22.9 ccl ile menekşede belirlenmiştir. Çalışma sonuçları türler arasında klorofil miktarı bakımından istatistiki olarak anlamlı düzeyde farklılıklar olduğunu ortaya koymaktadır. 
Varyans analizi sonucunda türler arasında hem güneşli alan hem de gölge koşullarında büyüyen yapraklar bakımından istatistiki olarak \%99.9 güven düzeyinde farklılıklar olduğunu göstermektedir. Yapılan Duncan testi sonucunda türler her iki yaprak bakımından da 7 homojen grupta toplanmıștır.

Yapilan varyans analizi sonucunda sadece orman sarmaşı̆̆ı, kurtbağnı ve sarı çiçekli yasemen bakımından güneşlenmeye bağl1 olarak yapraklar arasinda istatistiksel olarak en az $\% 95$ güven düzeyinde farklılıklar olmadığı, diğer türlerde ise güneș alan yapraklar ile gölge koşullarında yetişen yapraklar arasında klorofil miktarı bakımından istatistiksel olarak en az \%95 güven düzeyinde anlamlı farklılıklar olduğu tespit edilmiştir. Söz konusu türlerde güneş ve gölge yaprakları arasındaki fark menekşede \%95, dağ muşmulası ve süsende $\% 99$ ve diğer türlerde $\% 99.9$ güven düzeyinde anlamlıdır.

\section{Sonuç ve Öneriler}

Yapraklardaki klorofil miktarı pek çok çevresel faktörden etkilenerek değişiklik göstermektedir. Bunların yanında bitki türü ve yaprağın pozisyonunun da yapraktaki klorofil miktarını etkilediği bilinmektedir (Gond ve ark., 2012). Kurtar (2012) gölge ve 1şık gören yaprakların farklı bir iç ve dış yapıya sahip olduğunu, fazla 1 ş̧ koşullarında yetişen bitkilerin dayanıklılı̆̆ını sağlayan dokuların iyi geliştiğini, kloroplastların az sayıda fakat büyük olduğunu ve klorofil miktarlarının fazla olduğunu belirtmektedir.

Çalıșma sonucunda bazı türlerde güneș alan yapraklarda klorofil miktarının, bazı türlerde ise gölge koşullarında yetişen yaprakların klorofil miktarının daha yüksek olduğu görülmektedir. Öncel ve ark., (2004) bitkilerin güneşli bir gündeki güneş 1 şı̆̆ının maksimum $1 / 10$ unda fotosentez yapabildiklerini, bu değerin altında fotosentezin 1 şık ile sinırlandığını belirtmektedir. Dolayısıyla güneşlenme süresi ile fotosentezin ve buna bağlı olarak da klorofil miktarının doğru orantılı olarak artmasını beklemek yanlıştır. Işık şiddeti ile fotosentez arasinda doğrusal bir korelasyon vardır. Hem güneş hem de gölge bitkilerinde 1şık şiddetine bağlı olarak fotosentez hızında da bir artış olur. Ancak, bu artış sonsuz olmayıp belirli bir sınır vardır ve üst sınır gölge bitkilerinde güneş bitkilerine oranla daha düşüktür (Aksay ve ark., 2009). Ayrıca fotosentezde diffuz 1şığın etkileri de göz önünde bulundurulmalıdır.

Fotosentezde direkt 1 șik ve diffuz 1 șik arasında fizyolojik bakımdan, dolayısıyla fotosentezdeki etkileri bakımından farklar vardır. Doğrudan doğruya gelen güneş ışınlarında fizyolojik bakımdan aktif ışınlarının miktarının \% 35, diffuz yolu 1şınlarında ise bu oran \% 50-60 olduğu tespit edilmiştir. Fotosentez üzerinde 1şı cinsi ile birlikte 1şık miktarı veya şiddeti, aydınlanma süresi, toprak özellikleri de rol oynar (Kurtar, 2012).

Farklı gölge koşullarının yapraklardaki klorofil üzerindeki etkileri pek çok çalışmada ortaya konulmuştur. Johnston ve Onwueme (1998) patates, Dai ve ark., (2009) Tetrastigma hemsleyanum, Khan ve ark. (2000) Pinus ponderosa, Pseudotsuga menziesii, Thuja plicata ve Tsuga heterophylla, Güneş ve İnal (1995) Triticum aestium L., Sevik ve ark., (2012) Mahonia aquifolium, Juglans nigra, Aesculus hippocastanum, Cornus mas, Cydonia oblonga, Betula pendula, Tilia tomentosa, Morus nigra, Berberis thunbergii, Buxus sempervirens, Corylus colurna, Acer pseudoplatanus, Ailanthus altissima, Laburnum anagyroides, Celtis australis, Lonicera tatarica, Salix matsudana, Ulmus campestris, Cercis siliquastrum ve Robinia pseudoacacia üzerinde yaptıkları çalışmalarda gölgeleme veya 1şık miktarının bitkiler üzerindeki etkilerini ortaya koymuşlardır.

Iş1k şiddetinin sınır değeri bitki türlerine, özellikle 1şık ve gölge bitkilerine göre değişir. Işık şiddetinin artışına paralel olarak fotosentez miktarının artışı bitki türlerine göre çok değişmektedir. Örneğin Pinus taeda fidecikleri \% 100 1şığa kadar 1şık artışına paralel olarak fotosentez yaptığ 1 halde, yapraklı türlerin birçoğu $\% \quad 30 \quad 1 s ̧ 1 k$ miktarında fotosentezlerini en yüksek değerine ulaştırırlar (Kurtar, 2012).

Çalışmada bitki türleri arasında klorofil miktarı bakımından büyük farklar bulunduğu belirlenmiştir. Güneş alan yapraklarda en 
yüksek ortalama klorofil değeri $140.9 \mathrm{ccl}$ ile taflanda, en düşük klorofil değeri ise $14.9 \mathrm{ccl}$ ile süs lahanasında belirlenmiştir. Gölge koşullarındaki yapraklarda ise en yüksek klorofil değeri $140.3 \mathrm{ccl}$ ile yine taflanda, en düşük klorofil değeri ise $22.9 \mathrm{ccl}$ ile menekşede belirlenmiştir. $\mathrm{Bu}$ durum türler arasında klorofil miktarı bakımından büyük farklar olabileceğini göstermektedir. Benzer sonuçlar başka çalışmalarda da elde edilmiştir (Sevik ve ark., 2013; Sevik ve ark., 2014).

Klorofil miktarının tespiti uygulamada pek çok alanda kullanılabilir. Yeşillik klorofil içeriği yaprak absorptansını ve herhangi bir olay 1şık kullanılabilirlik için emilen 1şık dolayısıyla kısmını belirler (Niinemets 2010). Klorofil miktarı bitkinin soğuğa toleransının belirlenmesinde de bir göstergedir (Perks ve ark., 2004). Demirel ve ark., (2010) karpuz bitkisinde klorofil okumalarının özellikle çiçeklenme dönemi ve meyve oluşum döneminin başlangıcında su stresini belirlemek için kullanılabileceğini belirtmektedirler. Knudson (1977) klorofil tayini ile fasulye yapraklarında meydana gelen ozon zararının kesin ve pratik olarak ölçülebileceğini belirtmektedir.

Rose ve Haase (2002) göre bunlar dondurma maruz kaldıktan sonra fide gücü hızlı bir değerlendirme sağlamak için klorofil flüoresans ölçümü, strese soğuğa karş1 dayanıklılığı ve direncini belirlemek için yararlı olduğu bildirilmiştir.

Fakat klorofil miktarını etkileyen pek çok faktör bulunmaktadır. Klorofil miktarının uygulamada etkin olarak kullanımı için bu konudaki çalışmaların artırılarak ve çeşitlendirilerek devam etmesi gerekmektedir.

\section{Kaynaklar}

Aksay, C.S., Ketenoğlu, O., Kurt, L. 2009. Işı1k kirliliği, Afyon Kocatepe University Journal of Science, 7(2), 231-236

Belkayali N. Kesimoglu M.D. 2015. The stakeholders' point of view about the impact of recreational and tourism activities on natural protected area: a case study from Kure Mountains National Park, Turkey, Biotechnology \& Biotechnological Equipment, 29(6), 1092-1103.
Burchett, M., Torpy, F., Brennan, J., Craig, A. 2014. The influence of office plants in reducing feelings of stress and negativity in building occupants (Basım aşamasında).

Cetin M. 2015a. Using GIS analysis to assess urban green space in terms of accessibility: case study in Kutahya. International Journal of Sustainable Development \& World Ecology, 22(5), 420424.

Cetin M. 2015b. Determining the bioclimatic comfort in Kastamonu City. Environmental Monitoring and Assessment., 187(10), 640. DOI: 10.1007/s10661-0154861-3

Cetin M. 2015c. Evaluation of the sustainable tourism potential of a protected area for landscape planning: a case study of the ancient city of Pompeipolis in Kastamonu. International Journal of Sustainable Development \& World Ecology, 22(6), 490-495. DOI: 10.1080/13504509.2015.1081651

Chang C.Y., Chen P.K. 2005. Human response to window views and indoor plants in the workplace. HortScience, 40 (5), 13541359.

Dai, Y.J., Shen, Z.G., Liu, Y., Wang, L.L., Hannaway, D., Lu, H.F. 2009. Effects of shade treatments on the photosynthetic capacity, chlorophyll fluorescence, and chlorophyll content of Tetrastigma hemsleyanum Diels et Gilg, Environmental and Experimental Botany, 65(2-3), 177-182

Demirel, K., Genç, L., Çamoğlu, G., Aşı1k, Ş. 2010. Assessment of water stress using Chlorophyll readings and leaf water content for watermelon, Journal of Tekirdag Agricultural Faculty, 7(3), 155-162

Djukanovic R, Wargocki P, Fanger P.O. 2002. Cost-benefit analysis of improved air quality in an office building. Proceedings: Indoor Air, 2002, 808-813.

Gond, V., DePury, D.G.G., Veroustraete, F., Ceulemans, R. 2012. Seasonal variations in leaf area index, leaf chlorophyll, and water content; scaling-up to estimate fAPAR and carbon balance in a multilayer, multispecies temperate forest, Tree Physiology, 19(10), 673-679

Güneş, A., İnal, A. 1995. The effect of foliar applied glucose on the yield and chlorophyll content of wheat (Triticum 
aestium L.) grown at different photoperiods, Pamukkale University Engineering College Journal of Engineering Science, 1(1), 69-72 Ankara

Johnston, M., Onwueme, I.C. 1998. Effect of shade on Photosynthetic pigments in the tropical root crops: Yam, taro, tannia, cassava and sweet potato, Experimental Agriculture, 34(3), 301-312

Khan, S.R., Rose, R., Haase, D.L., Sabin, T.E. 2000. Effects of shade on morphology, chlorophyll concentration and chlorophyll fluorescence of four pacific northwest conifer species, New Forests, 19, 171-186

Knudson L.L., Tibbitts T.W., Edward G.E. 1977. Measurement of ozone injury by determination of chlorophyll concentration. Plant Physiology. 60, 606-608.

Kurtar, E.S., 2012. Sera Ekolojisi Ders Notları, Ondokuz Mayıs Üniversitesi, Bafra Meslek Yüksek Okulu, 72 p., Samsun

Küçük, V., Gül A., 2005, Isparta kentiçi yol ağaçlandirmalari üzerine bir araştirma. Süleyman Demirel Üniversitesi, Fen Bilimleri Enstitüsü Dergisi, 9-3 (2005),111118.

Lohr V.I., Pearson-Mims C.H., Goodwin G.K. 1996. Interior plants may improve worker productivity and reduce stress in a windowless environment. Journal of Environmental Horticultural, 14(2), 97-100.

Niinemets, Ü., 2010. A review of light interception in plant stands from leaf to canopy in different plant functional types and in species with varying shade tolerance, Ecological Research, 25(4), 693-714

Ozturk S, Bozdogan E. 2015. The contribution of urban road trees on improving the air quality in an urban area. Fresenius Environmental Bulletin, 24 (5A), 1822-1829.

Öncel, I., Üstün, S., Keleş, Y., 2004. Fotosentez, Bitki Fizyolojisi Laboratuvar Kılavuzu, A.Ü.F.F. Döner Sermaye İşletme Yayınları, 48, 76-77. Ankara

Papinchak H, Holcomb E.J., Orendovici B.T., Decoteau, D.R. 2009. Effectiveness of houseplants in reducing the indoor air pollutant ozone. HortTechnology, 19(2), 286-290.

Perks, M.P., Osborne, B.A., Mitchell, D.T. 2004. Rapid predictions of cold tolerance in Douglas-fir seedlings using chlorophyll fluorescence after freezing, New Forests, 28(1), 49-62

Rose, R., Haase, D. 2002. Chlorophyll fluorescence and variations in tissue cold hardiness in response to freezing stress in douglas-fir seedlings, New Forests, 23(2), 81-96

Sevik, H., 2011. Dallanma karakterleri bakimindan noel ağaci üretimine uygun uludağ göknari populasyonlarinin belirlenmesi, Kastamonu Üniversitesi, Orman Fakültesi Dergisi, 11(1), 102-107, Kastamonu.

Sevik, H. 2012. Variation in seedling morphology of Turkish fir (Abies nordmanniana subsp. bornmulleriana Mattf), African Journal of Biotechnology, 11(23), 6389-6395.

Sevik, H., Guney, D., Karakas, H., Aktar G. 2012. Change to amount of chlorophyll on leaves depend on insolation in some landscape plants, International Journal of Environmental Sciences, 3(3), 1057-1064

Sevik, H., Karakaş, H., Karaca Ü. 2013. Color - Chlorophyll relationship of some indoor ornamental plant, International Journal of Engineering Science \& Research Technology, 2(7), 1706-1712

Sevik, H., Belkayalı, N., Aktar G. 2014, change of Chlorophyll amount in some landscape Plants, Journal of Biotechnological Sciences, 2(1), 10-16

Sevik H, Cetin M, Belkayali N. 2015. Effects of forests on amounts of $\mathrm{CO}_{2}$ : case study of Kastamonu and Ilgaz Mountain National Parks. Polish Journal of Environmental Studies, 24 (1), 253-256.

Talay İ, Kaya F, Belkayalı N. 2010. Socio-economic structure effects on the recreational trends and demands: a case study Bartin city. Journal of Geographical Sciences, 8(2), 147-156.

Tani A, Hewitt C.N. 2009. Uptake of aldehydes \& ketones at typical indoor concentrations by houseplants. Environmental Science and Technology, 43 (21), 8338-8343.

Tekce N, Belkayali N, Oğuz D, Baştemur C.T. 2010. A survey on recreational use of domestic water supply reservoirs: A case study from Kurtboğazi-Ankara, Turkey. African Journal of Agricultural Research, 5(14), 1897-1907 
Turna İ, Güney D. 2009. Altitudinal variation of some morphological characters of Scots Pine (Pinus sylvestris L.) in Turkey. African Journal of Biotechnology, 8(2), 202208.

Yang, D. S., Pennisi, S. V., Son, K-C., Kays, S. J., 2009. Screening indoor plants for volatile organic pollutant removal efficiency', HortScience, 44(5), 1377-1381.

Yakar, N., Bilge, E., 1987. Fotosentez, Genel Botanik, İstanbul Universitesi, Fen Fakültesi Yayınları, ISBN: 975-404-016-8, İstanbul.

Yigit N, Öztürk A, Sevik H. 2014. Ecological impact of urban forests (Example of Kastamonu urban forest). International Journal of Engineering Sciences \& Research Technology, 3(12), 558-562. 